\title{
Intercultural Communication and Work Integrated Learning: A South African Perspective
}

\author{
*Nisha Ramlutchman, Dayaneethie Veerasamy \\ Durban University of Technology, South Africa \\ *nishar@dut.ac.za
}

\begin{abstract}
Over the past decade, higher education institutions in South Africa have begun the shift towards a more structured work integrated learning framework, merging an academic component with specific industry requirements. Stemming from an ethnically diverse South African society, the South African corporate sector is made up of a group of varied individuals who bring with them specific cultural dynamics to the working environment. This paper investigates the intercultural communication sensitivity of students during their work integrated learning training, resulting in a discussion on the value for integrating intercultural education at a tertiary curricula level. The study is located at the Durban University of Technology. The study was quantitative and descriptive in nature. A total of 189 questionnaires were completed and returned by students who completed their work integrated learning (WIL) training during 2010. The intercultural sensitivity scale developed by Chen and Starosta was used in the questionnaire to measure the intercultural sensitivity level of these students during their WIL training. The results showed that the students were comfortable engaging with different cultural groups during their WIL training, students also attached a high value to the respect for cultural differences and they found the experience of interacting with people from different cultures uplifting
\end{abstract}

Keywords: Work integrated learning (WIL), intercultural communication sensitivity, intercultural communication education

\section{Introduction}

The expansion of the global workforce across political, economic, social and cultural boundaries has brought about increasingly diverse and multicultural business environments. South Africa, a country with diverse race groups and cultures, has a corporate sector that is made up of a group of varied individuals who bring with them specific cultural dynamics to the working environment. During the apartheid regime, South Africa's business environment was culturally divisive, with very limited interaction between workers of diverse cultures. Over the past decade, as the country shifted towards political democracy, the business environment also saw (and continues to see) a marked shift, particularly in terms of the integration of various cultures in the business environment. Dealing with people from other cultures in the work environment demands knowledge and training in intercultural communication skills. In response to the country's political changes, higher education institutions in South Africa have also undergone, and continue to undergo, processes of change at various structural and curricula levels. One resultant change is the shift towards a more structured work integrated learning framework, merging an academic component with specific industry requirements. Research into this area tends to focus more on developing a pedagogical framework that is geared towards an authentic learning environment. An area that is under researched is the intersection between intercultural communication and work integrated learning at a curricula level, which is of particular significance in South Africa, taking into account the country's multicultural environment. Racial segregation of South African schools and tertiary institutions is synonymous with the Apartheid regime. With the disintegration of Apartheid in 1994, the South African education system has officially brought about the demise of racially segregated education. Whilst this is a 'technically' correct process, i.e. opening educational institutions to all racial groups, the 'practice' of (especially) fully integrated schools and, to a lesser extent, universities hinges on various factors. For example, geographic location, economic status and language barriers still pose a great threat to a fully integrated, unitary system of South African education.

A marked lack of integrated learning at primary and secondary levels of education in South Africa schools (c.f. Enoch, 2007), results in many students encountering, perhaps for the first time, a more significant racially integrated learning environment at a tertiary level. Previous studies (c.f. Dixon, Tredoux \& Clack, 2005; Durheim, 2005) have shown however, that a physically racially integrated environment does not always result in psychological integration. Jansen (2004) argued that whilst the South African education system had made impressive democratic strides, the country had a long road ahead in terms of outlining 
actual democratic procedures within schools and universities. Jansen (2004) further argues that schools and universities remain the 'lifeblood' of South Africa's young democracy and education impacts greatly on the choices South Africa's youth make, including respect for other cultures in both social and work contexts. Within the context of a changing educational environment, tertiary educators thus face the challenges of an increasingly diverse student population. Another pressing concern for higher education is that the Higher Education Minister indicated several government initiatives to increase the number and quality of university graduates in South Africa. It was stated that a shortage of skills remained one of the country's biggest hurdles to economic growth and job creation. The government's new economic growth path, launched in 2010, highlighted the shortage of skilled artisans, workers and professionals as a key constraint to reducing South Africa's unemployment rate from 25 percent to 15 percent by 2020 (South Africa info, 2010). For South Africa's universities of technologies (UoTs) this is of particular importance as traditionally, UoTs are seen as providing more practical education that gears students for the work environment. UoTs, like the Durban University of Technology, focus on authentic learning strategies, like Work Integrated Learning, which are framed around real-life work contexts. Whilst the focus on work experience is impressive, educational strategies focusing on intercultural communication skills is equally important when taking into consideration South Africa's multicultural context. Evaluating students' intercultural communication competence is one step towards promoting the value of intercultural communication education in higher education. This paper sets out to investigate the intercultural communication sensitivity of students at the Durban University of Technology during their work integrated learning training. The paper also discusses the value of integrating intercultural education at a tertiary curricula level.

\section{Literature Review}

Intercultural Communication Competence: An important aspect of intercultural communication is intercultural communication competence (ICC), which is "the ability to communicate effectively in crosscultural situations and to relate appropriately in a variety of cultural contexts" (Bennett and Bennett, 2004). ICC has been the focus of a number of studies in areas like international management, culture shock, cross-cultural training, intergroup contact and immigrant acculturation (Wiseman, 2002). Essentially, though, ICC is connected with the concepts of culture and communicative competence. Intercultural implies an understanding of and interaction with 'other' cultures, values, attitudes, behaviours and so on, apart from one's own. Sercu (2005) defines intercultural communication competence as the "willingness to engage with the foreign culture, self-awareness and the ability to look upon oneself from the outside, the ability to see the world through the others' eyes, the ability to cope with uncertainty, the ability to act as a cultural mediator, the ability to evaluate others' points of view, the ability to consciously use culture learning skills and to read the cultural context, and the understanding that individuals cannot be reduced to their collective identities". In other words, intercultural competence requires culturally sensitive knowledge, using special skills to understand and appreciate other cultures. Furthermore, ICC is also defined as the acquiring of the "knowledge, motivation and skills to interact effectively and appropriately with members of different cultures" (Wiseman, 2002). Understanding and recognition of intercultural competence has gained increasing interest in both the educational and business sectors. Employers and educators believe that employees and learners need to be better prepared to function in multicultural environments (Sercu, 2004). Kuada (2001) states that "international managers are advised to substantially improve their intercultural competencies in order to enhance their performance".

The education sector places increasing emphasis on the need to train students for the global, multicultural workplace. In the United States education sector, for example, more focus is being given to "developing a global workforce that is interculturally competent to succeed in diverse work places" (Deardorff,2004). In terms of this paper and the focus on work integrated learning, understanding of intercultural competence could lead to students becoming more culturally sensitive, tolerant and accepting of other cultures during their work placement. South Africa's higher educational curricula should be responsive to the different racial, social, cultural and ethnic groups that exist in the workplace. Developing curricula that provides relevant and meaningful knowledge around intercultural sensitivity is thus vital in preparing students for not only the workplace, but also society at large. Chen and Starosta (1998) maintain that "academic exposure to the multicultural environment will provide students with the skills to excel in the real world. Because students ultimately return to a world outside the school, the more fully they learn to recognize and to respect differences in the beliefs, values and worldviews of people of varying cultural extraction the more effectively will they promote a multicultural society 
beyond the classroom". Students should therefore be made aware of intercultural communication competence and its value to specifically, gearing them for the workplace.

Approaches to Intercultural Communication Competence: Past approaches to research in intercultural communication competence (ICC) have been viewed through various theoreticallenses. Early investigations have explored the social network approach (Kim, 1986; Smith 1999) which looks at one's own personal network in enriching one's ability when communicating with other cultures. Subsequent studies include Gudykunst's $(1993 ; 1995)$ expansion of the uncertain reduction theory, which explores the high levels of anxiety and uncertainty often associated with intercultural communication. Another approach is Ting-Toomey's (1993) identity-negotiation to ICC, which examines the internal processes that one experiences in an intercultural context. Spitzberg (1997) adds to the field through the development of an integrative model of ICC that is represents three levels of analysis; the individual, episodic and relational systems. This paper uses Chen and Starosta's (1998) approach to ICC in exploring the intercultural communication competence of students during their work integrated learning training. Chen and Starosta (1998) explain intercultural communication competence as the "ability to effectively and appropriately execute communication behaviours to elicit a desired response in a specific environment". There are 3 perspectives to ICC, namely: Affective or Intercultural sensitivity - to acknowledge and respect cultural differences; Cognitive or intercultural awareness - self-awareness of one's own personal cultural identity and understanding how cultures vary and Behavioral or intercultural adroitness - message skills, knowledge of appropriate self-disclosure, behavioral flexibility, interaction management and social skills (Fritz, Möllenberg and Chen, 2000). In subsequent studies, Chen and Starosta (2000) developed an instrument to explore the concept of intercultural sensitivity, which looks at the emotional desire of a person to acknowledge, appreciate, and accept cultural differences. The instrument consists of 24 items that look at how people acknowledge, appreciate, and accept cultural differences.In South Africa, as diverse cultures continue to join the working environment, the opportunity to decrease the distance between these cultures presents itself. This calls for the development of intercultural understanding and sensitivity in order to live peacefully among and interact successfully with others who reflect unique and different cultures (Samovar, Porter and McDaniel, 2009). The primary purpose of this study is to investigate the intercultural communication sensitivity of students at the Durban University of Technology during their work integrated learning training.

Work Integrated Learning: Characteristics of universities of technology include a strong corporateorientation focus, relevance of programmes and responsiveness and fulfilment of the needs of industry, community and society (Du Pré, 2004). The link must be deliberately reinforced, and the Durban University of Technology (DUT) invests a lot into doing this and can therefore boast strong relationships with its partners, both locally and internationally. To achieve a satisfactory work integrated learning outcome, the DUT ensures that the workplace is approved before the student is placed. This is done by suitably qualified and experienced academic staff. The approval clearly indicates what outcomes may be achieved in that particular workplace and elicits a commitment from the industry or workplace. The process also indicates a shift from content learning to greater understanding of learning processes including reflection and critical thinking (Schaafsma, 1996). Once in the workplace, the students are regularly monitored by academic staffs that make scheduled visits to the workplace. Multiple methods of data collection, student-constructed evaluation, portfolios, programme-based assessment and competency-based evaluation are some of the assessment tools used. After they have completed WIL, students should be debriefed. This is an important feedback mechanism and also allows students to reflect on their placement, especially in the light of shared experiences of other students. All WIL students of DUT are registered with the university during their WIL training. One of the areas that require more focus is preparation of students with not only the necessary discipline-specific skills for the workplace, but also a 'psychological' preparation in terms of providing the relevant and meaningful curricula that addresses complex issues related to intercultural communication and diversity in the workplace.

\section{Methodology}

This study was conducted at the Durban University of Technology (DUT), using the Faculty of Management Sciences as a sample. The research was quantitative and descriptive in nature.

Sample: The sampling population consisted of all students in the Faculty who completed their work integrated learning training during 2010. A total of 189 questionnaires were completed and returned. Convenience sampling is the cheapest and easiest to conduct and was used to select the respondents. 
Instrument and procedure: The intercultural sensitivity scale developed by Chen and Starosta (2000) was used in the questionnaire to measure the intercultural sensitivity level of these students during their work integrated learning training. It is a pre-existing, validated instrument by virtue of its extensive use in a variety of settings. This intercultural sensitivity scale consists of 24 statements on a 5-point scale

Where $1=$ strongly disagree and $5=$ strongly agree. These 24 items are grouped under 5 major dimensions as follows:

Interaction Engagement: 7 questions

Respect for Cultural Differences: 6 questions

Interaction Confidence: 5 questions

Interaction Enjoyment: 3 questions

Interaction Attentiveness: 3 questions

Note: Items $2,4,7,9,12,15,18,20$, and 22 were reverse-coded before summing the 24 items (Fritz, Möllenberg and Chen, 2000).

Data analysis: The collected data was analyzed by using the Statistical Package for Social Sciences (SPSS) version 14.0 for Windows. The reliability of the scale was measured using Cronbach alpha.

\section{Results and Discussion}

Table 1 shows a summary of the data collected, using the five ICC dimensions identified above.

Table 1: Summary of data collected

\begin{tabular}{|c|c|}
\hline Dimensions/Items & Mean \\
\hline \multicolumn{2}{|l|}{ Interaction Engagement } \\
\hline "I enjoy interacting with people from different cultures". (item 1) & 4.50 \\
\hline "I tend to wait before forming an impression of culturally-distinct counterparts".(item 11) & 3.40 \\
\hline “I am open-minded to people from different cultures”.(item 13) & 4.13 \\
\hline "I often give positive responses to my culturally different counterpart during our interaction". (item 21) & 3.71 \\
\hline "I avoid those situations where I will have to deal with culturally-distinct persons". (item 22) & 2.62 \\
\hline $\begin{array}{l}\text { "I often show my culturally-distinct counterpart my understanding through verbal or nonverbal cues”. (item } \\
\text { 23) }\end{array}$ & 3.37 \\
\hline $\begin{array}{l}\text { "I have a feeling of enjoyment towards differences between my culturally-distinct counterpart and me". } \\
\text { (item 24) }\end{array}$ & 3.88 \\
\hline \multicolumn{2}{|l|}{ Respect for Cultural Differences } \\
\hline "I think people from other cultures are narrow-minded". (item 2) & 2.22 \\
\hline "I don't like to be with people from different cultures". (item 7) & 1.46 \\
\hline "I respect the values of people from different cultures".(item 8) & 4.49 \\
\hline "I respect the ways people from different cultures behave". (item 16) & 3.96 \\
\hline "I would not accept the opinions of people from different cultures". (item 18) & 1.75 \\
\hline "I think my culture is better than other cultures". (item 20) & 2.28 \\
\hline \multicolumn{2}{|l|}{ Interaction Confidence } \\
\hline “I am pretty sure of myself in interacting with people from different cultures". (item 3) & 4.25 \\
\hline "I find it very hard to talk in front of people from different cultures". (item 4) & 2.16 \\
\hline “I always know what to say when interacting with people from different cultures".(item 5) & 3.48 \\
\hline "I can be as sociable as I want to be when interacting with people from different cultures". (item 6) & 3.94 \\
\hline “I feel confident when interacting with people from different cultures".(item 10) & 3.79 \\
\hline \multicolumn{2}{|l|}{ Interaction Enjoyment } \\
\hline "I get upset easily when interacting with people from different cultures". (item 9) & 1.71 \\
\hline “I often get discouraged when I am with people from different cultures".(item 12) & 1.78 \\
\hline "I often feel useless when interacting with people from different cultures".(item 15) & 1.61 \\
\hline \multicolumn{2}{|l|}{ Interaction Attentiveness } \\
\hline “I am very observant when interacting with people from different cultures”. (item 14) & 3.88 \\
\hline "I try to obtain as much information as I can when interacting with people from different cultures". (item 17) & 4.03 \\
\hline "I am sensitive to my culturally-distinct counterpart's subtle meanings during our interaction". (item 19) & 3.10 \\
\hline
\end{tabular}

Interaction Engagement: The results showed that in the interaction engagement dimension, the mean for all but item 22 (reverse coded) is well above 3. For example, in the item "I enjoy interacting with people from different cultures", the mean is $4.50 .57 \%$ of the students chose "strongly agree", $39 \%$ of the students chose "agree", $3 \%$ of the students chose "uncertain", $1 \%$ of the students chose "disagree" and $1 \%$ 
of the students chose "strongly disagree". This result clearly suggests that the students are comfortable engaging with different cultural groups during their work integrated learning experience. Figure 1 below shows the response to item 22, "I avoid those situations where I will have to deal with culturally-distinct persons". 30\% of the students chose "uncertain", 20\% chose "agree" and 3\% chose "strongly agree". This result indicates the possibility that students experience some levels of uncertainty when having to deal with culturally-distinct persons. This data is also consistent with Gudykunst's $(1993,1995)$ anxiety/uncertainty management theory, which explores the high levels of anxiety and uncertainty often associated with intercultural communication. Developing intercultural communication curricula focusing on dealing with different cultures in the workplace would thus assist students in understanding and dealing with the complexities of working in a culturally diverse business environment.

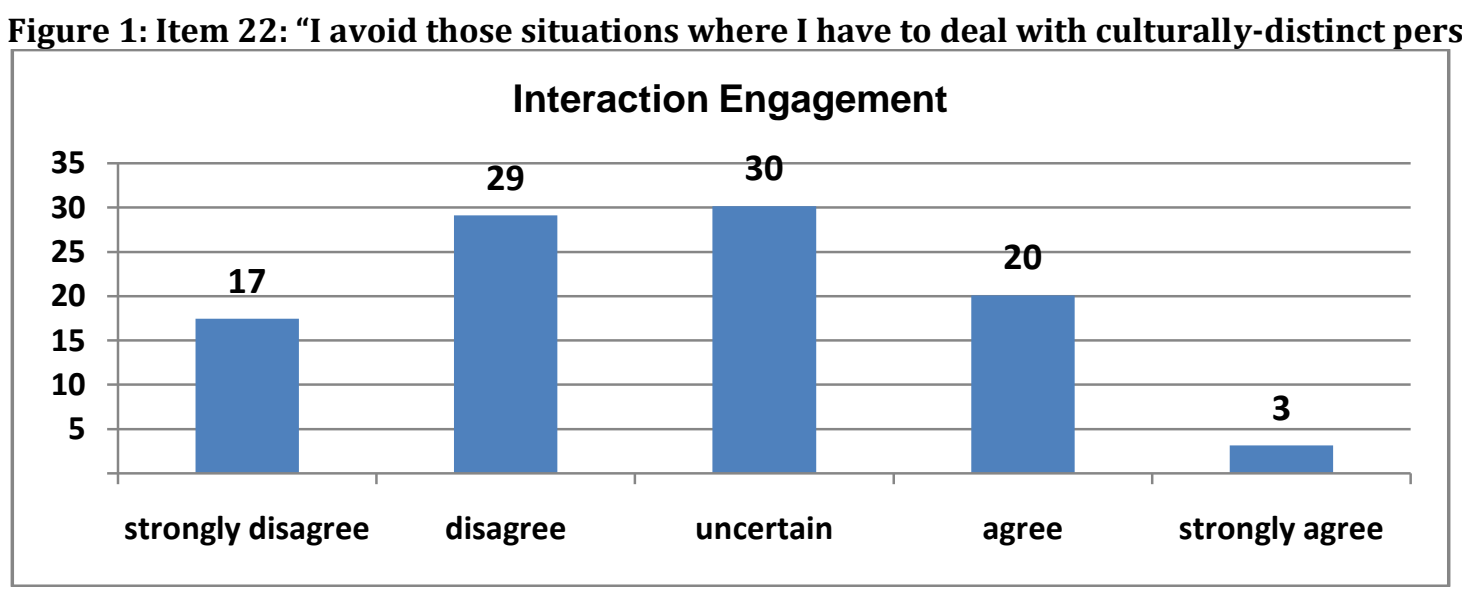

Respect for Cultural Differences: This dimension includes 6 items. In the item "I respect the values of people from different cultures" (item 8) the mean is 4.49 and "I respect the ways people from different cultures behave" (item 16) the mean is 3.96. Figure 2 below outlines the students' percentages for these two items. This result shows that students attach a high value (in terms of percentage) to the respect for cultural differences during their WIL training. These findings emphasise an important issue raised in Durocher's (2009) pilot study which looked at addressing problems of intercultural communication competence in business students. Durocher (2009) refers to Bennett's (1993) 'Developmental Model of Intercultural Sensitivity', that explains the "stages through which individuals pass as they develop intercultural competence". Durocher (2009) relates the respect for cultural difference to the minimisation stage, whereby individuals "tend to minimise the importance of cultural difference." Durocher (2009) further explains that although the findings may suggest an increase in sensitivity to cultural difference, "it is still an ethnocentric world-view because the presumed sameness is inevitably grounded in the individual's own cultural values and assumptions". Thus, although the majority of students in this study indicate a respect of culturally diverse people, the issue of minimisation needs to be more carefully examined, which can possibly be addressed through the design of intercultural communication curricula that focuses on concepts like ethnocentrism and ethnorelativism.

Figure 2: Item 8 "I respect the values of people from different cultures" and Item 16 "I respect the ways people from different cultures behave"

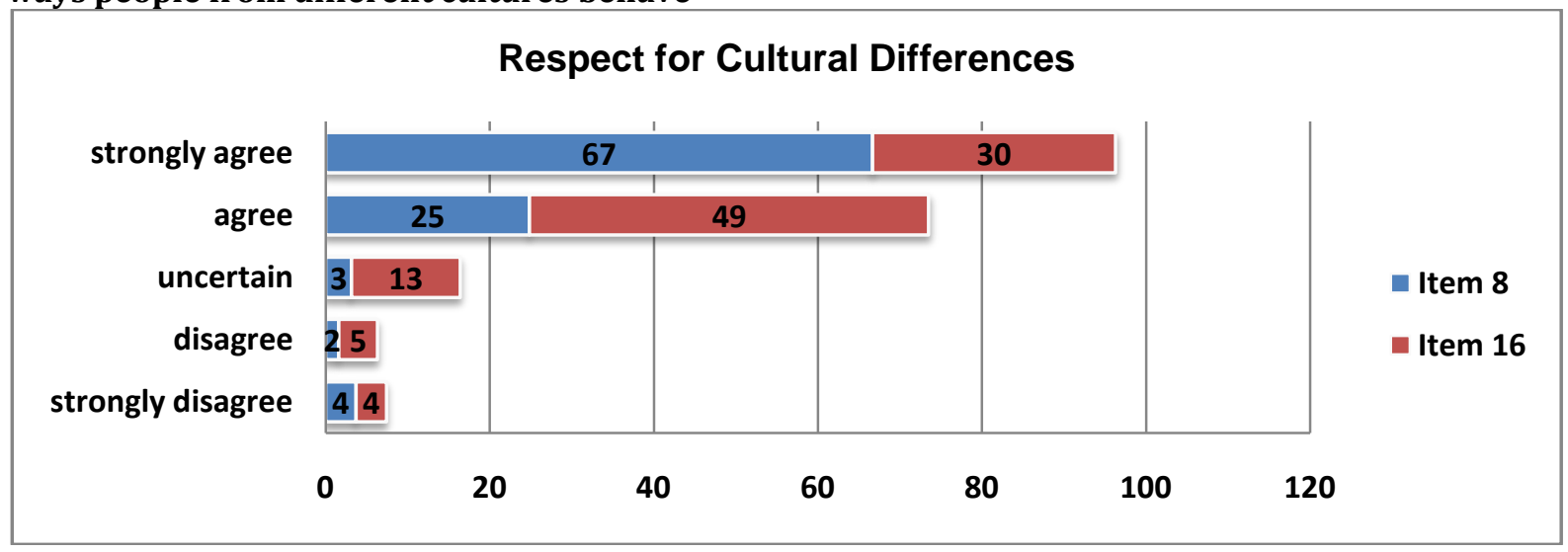


Interaction Confidence: The results showed that in the interaction confidence dimension, the mean for all but item 4 (reverse coded) is above 3. For example, in the item "I am pretty sure of myself in interacting with people from different cultures" (item 3), the mean is $4.25 .39 \%$ of the students chose "strongly agree", $50 \%$ chose "agree", $9 \%$ chose "uncertain" and $2 \%$ chose "strongly disagree". No students selected "disagree". This result shows that students are confident when interacting with people from different cultures during their WIL training. The item "I always know what to say when interacting with people from different cultures" (item 5) yielded a lower confidence response in terms of the rest of the items. Figure 3 below illustrates this.

Figure 3: Item 5: "I always know what to say when interacting with people from different cultures"

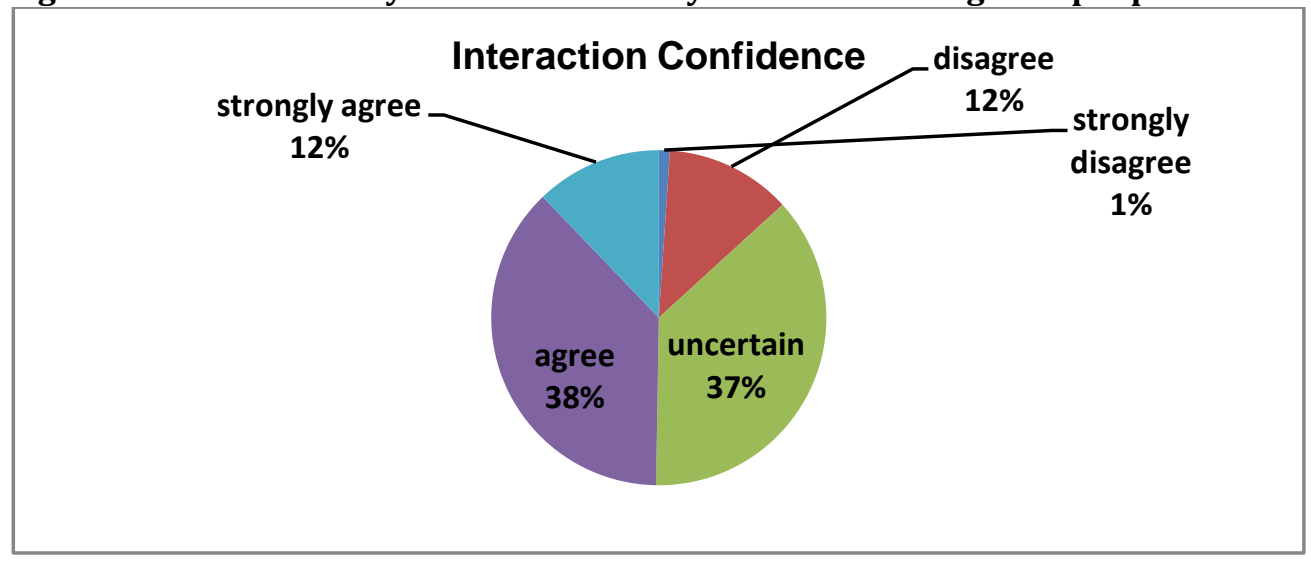

This result shows that a fairly large percentage of students (37\%) are still uncertain when it comes to verbally expressing themselves when interacting with people from different cultures. A possible reason for this could be the nature of the working experience, in that the student is in essence, an intern, and in training mode. Some students might experience more difficulty in expressing themselves with other cultures, considering their entry level (junior) position in their respective work environment. Educational strategies that incorporate intercultural communication skills could also look at how factors such as age, gender, language and designation impact on the work environment. Such a focus would be aimed at increasing students' confidence when dealing with different cultures.

Interaction Enjoyment: In this dimension, all items (9,12 and 15) were reverse-coded. For example, the item "I often feel useless when interacting with people from different cultures" (item 15) has a mean of 1.61. $53 \%$ of the students chose "strongly disagree", $36 \%$ chose "disagree", $7 \%$ chose "uncertain", $3 \%$ chose agree and $1 \%$ chose "strongly agree". The results show that the students find the experience of interacting with people from different cultures uplifting and view this interaction in a positive light. In terms of intercultural communication education, the level of enjoyment experienced when working with other cultures plays an important role in possibly breaking away from negative social stereotypes and prejudices that often transfer to the workplace. As a result of South Africa's apartheid system and its then racial segregation policy, many South Africans still experience (sometimes latent) preconceived notions about race and culture. Students should therefore be educated on understanding how, for example, issues around stereotypes, prejudice, and discrimination may appear in workplace situations.

Interaction Attentiveness: The results showed that in the interaction attentiveness dimension, the mean for all items is well above 3 . The results (Figure 4) show that the students are culturally mindful, possibly viewing the interaction with different cultures as a learning opportunity. The results of a study using a German sample confirmed the validity of the overall structure of Chen and Starosta's instrument on the measurement of intercultural sensitivity. The reliability of several indicators was not substantially high and the discriminant validity of the factors "Interaction Enjoyment" and "Interaction Attentiveness" was rather low. The lack of independence for the two factors might be caused by the low Eigen value in Chen and Starosta's model. A possible improvement of the model for future research is to combine the two factors into a single one or to develop better measurement concepts for both factors (Fritz, Möllenberg and Chen, 2000). 
Figure 4: Item 14: "I am very observant when interacting with people from different cultures" and Item 17: "I try to obtain as much information as I can when interacting with people from different cultures".

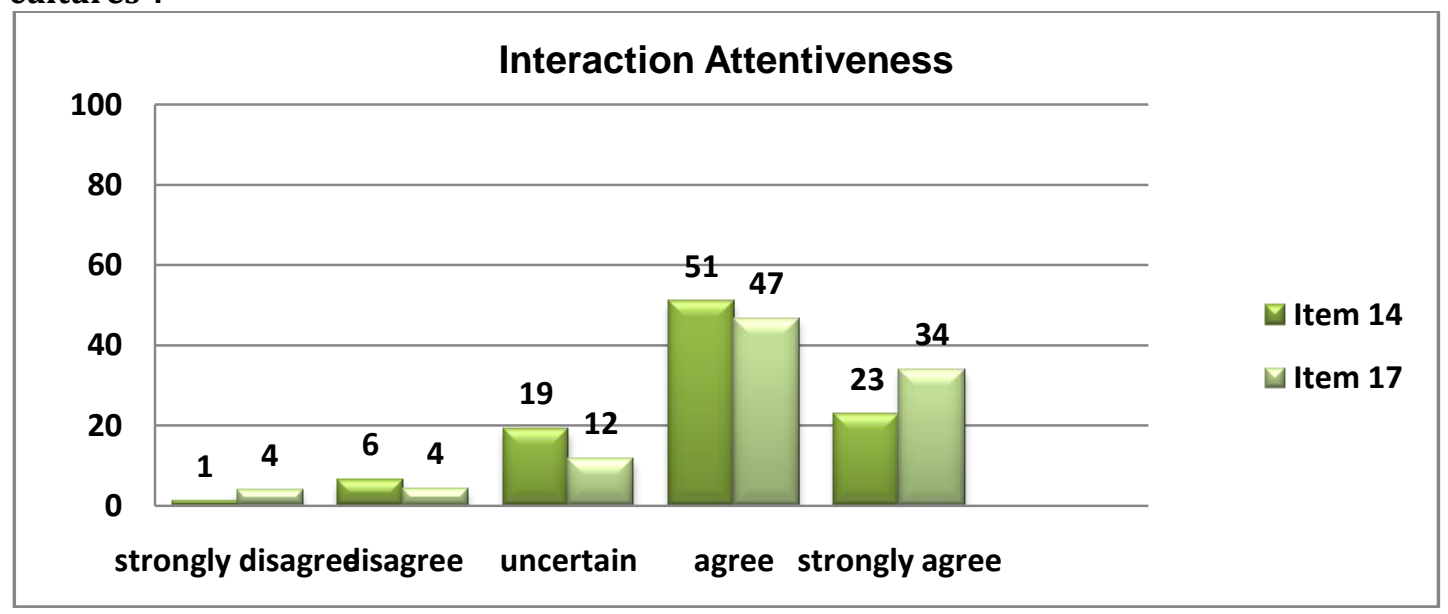

Item 19; "I am sensitive to my culturally-distinct counterpart's subtle meanings during our interaction" (Figure 5, below) shows that the students may have experienced some misunderstanding or misinterpretation of 'subtle meanings' amongst culturally-distinct people.

Figure 5: Item 19: “I am sensitive to my culturally-distinct counterpart's subtle meanings during our interaction"

\begin{tabular}{|ll|}
\hline Culturally-distinct counterpart \\
\\
\end{tabular}

$37 \%$ of the students chose "uncertain" $24 \%$ of the students chose "disagree" and 5\% chose "strongly disagree". The results show that students experience some degree of insensitivity and inattentiveness when it comes to understanding the more subtle messages when interacting with people from other cultures. Including curricula on intercultural communication skills, and particularly on understanding the nuances of dealing with diverse cultures, is thus imperative for preparing South African students for the workplace. In doing so, students will benefit from a more holistic education that is geared towards better and enhanced workplace interaction amongst diverse groups of people.

\section{Conclusion}

For the Interaction Engagement dimension, results showed that the students were comfortable engaging with different cultural groups during their WIL. However, some students experienced levels of uncertainty when having to deal with culturally-distinct persons. From this it is clear that intercultural communication curricula focusing on cultural differences, as well as exploring cultural similarities, will assist students in communicating and dealing with people from other cultures. According to the Respect for Cultural Differences dimension, students attached a high value to the respect for cultural differences during their WIL training. This shows that students are aware and respectful of cultural differences. This is a positive step towards understanding each other and establishing a positive working environment. Linking the idea of cultural respect to the business environment in terms of a structured curricula focus 
would provide students with meaningful knowledge that is hinged on developing the more widely acceptable work practices and behaviour. The result of Interaction Confidence dimension showed that whilst students are confident when interacting with people from different culture during their WIL training, 37\% are still uncertain when it comes to verbally expressing themselves when interacting with people from different cultures. This could be attributed to language differences since South Africa has eleven (twelve, when including sign language) official languages. Whilst English is the most commonly spoken language in the South African workplace, it is only the sixth most spoken home language.

In terms of the Interaction Enjoyment dimension, students found the experience of interacting with people from different cultures uplifting. This bodes well for the future, as South African organisations may gain a competitive advantage on the premise of value in diversity. Intercultural communication curricula that is framed to include positive examples of cultural integration in the workplace would also aid in mentally preparing students and building their confidence for entering the business environment, especially those who may be apprehensive (like in terms of 'acceptable' standards of behaviour, attitudes) about encountering diversity in the workplace. The Interaction Attentiveness dimension indicated that the students are culturally mindful, possibly viewing the interaction with different cultures as a learning opportunity. This result is positive and can lead to sharing of ideas by people from different cultural backgrounds which will enable efficiency in communication. Including curricula on intercultural communication at a tertiary level in South Africa would not only equip students with the skills to the meet the needs of a culturally diverse society (including the workplace) but would also promote a sense of pride in cultural pluralism.

\section{References}

Bennett, J. M. (1993). Towards Ethnorelativism: A Developmental Model of Intercultural Sensitivity, in Paige, M.R (ed.), Education for the Intercultural Experience, 109-135. Yarmouth, ME: Intercultural Press.

Bennett, D. L. J. \& Bennett, M. (2004). Handbook of Intercultural Training. $3^{\text {rd }}$ edition. Thousand Oaks, CA: Sage.

Chen, G. M. \& Starosta, W. J. (1998). A review of the concept of intercultural sensitivity. Human Communication, 1, 1-16.

Chen, G. M. \& Starosta, W. J. (2000). The development and validation of the intercultural communication sensitivity scale. Human Communication, 3, 1-15.

Deardorff, D. K. (2004). The Identification and Assessment of Intercultural Competence as a Student Outcome of Internationalization at Institutions of Higher Education in the United States. Unpublished PhD Dissertation, North Caroline State University, Raleigh. [Online] Available from: http://repository.lib.ncsu.edu/ir/handle/1840.16/5733 [Accessed 18 June 2011]

Dixon, I., Tredoux, E. \& Clack, E. (2005). On the micro-ecology of racial division: A neglected dimension of segregation. Journal of Psychology, 35, 395-411.

Du Pré, R. (2004). Universities of Technology in South Africa: Position, role and function. Johannesburg: Vaal University Press.

Durheim, K. (2005). Socio-spatial practice and racial representations in a changing South Africa. Journal of Psychology, 35, 444-459.

Durocher, D. O. (2009). Teaching Intercultural Communication Competence to Business Students. Journal of International Business Education, 4, 119-134.

Enoch, S. D. (2007). Guidelines for Multicultural Education in Integrated Schools with Specific Reference to the South African Context. Unpublished dissertation, University of Zululand, KwaZulu-Natal.

Fritz, W., Möllenberg, W. \& Chen, G. M. (2000). Measuring Intercultural Sensitivity in Different Cultural Context. [Online]. Available from www.wiwi.tubs.de/marketing/publikationen/ap/download/AP00-11.pdf

Gudykunst, W. B. (1995). Anxiety/uncertainty management (AUM) theory: Current status' in R. L. Wiseman (ed.), Intercultural communication theory, (8-58). Thousand Oaks, CA: Sage.

Gudykunst, W. B. (1993). Toward a theory of effective of effective interpersonal and intergroup communication: An anxiety/uncertainty management perspective, in R. L. Wiseman \& J. Koester (eds.), Intercultural communication competence, (33-71). Newbury Park, CA: Sage.

Jansen, J. D. (2004). Race, education and democracy after ten years: How far have we come? Lessons from the field: A decade of democracy in South Africa. [Online]. Available from www.idasa.org/media/uploads/outputs/files/Page\%2008.pdf [Accessed 11 January 2011] 
Kim, Y. Y. (1986). Understanding the social structure of intergroup communication', in W.B Gudykunst (ed.), Intergroup Communication. London: Edward Arnold.

Kuada, J. (2001). Intercultural competence development of Danish managers. International Business Economy Working Paper Series No. 33. [Online]. Available from http://www.google.co.za/url?sa=t\&rct=j\&q=\&esrc=s\&source=web\&cd=5\&ved=0CEoQFjAE\&url=h ttp\%3A\%2F\%2Fciteseerx.ist.psu.edu\%2Fviewdoc\%2Fdownload\%3Fdoi\%3D10.1.1.197.252\%26r ep\%3Drep1\%26type\%3Dpdf\&ei=qV8hUZvYHom2hQfPiIDIBw\&usg=AFQjCNHDYDnK6egdOGSDl_ Msny6-tZZutA\&bvm=bv.42553238,d.ZG4[Accessed 16 April 2011]

Samovar, L. A., Porter, R. E. \& Mcdaniel, E. R. (2009). Communication between Cultures. London: Wadsworth.

Schaafsma, H. (1996). Reflections of a visiting co-op practitioner. Journal of Co-operative Education, 31(23), 83-100.

Sercu, L. (2005). Teaching foreign languages in an intercultural world', in L. Sercu, E. Bandura, \& P. Castro (eds.), Foreign language teachers and intercultural competence: An international investigation. Ohio: Multilingual Matters.

Sercu, L. (2004). Assessing intercultural competence: a framework for systematic test development in foreign language education and beyond. Intercultural Education, 15(1), 73-89.

Smith, L. R. (1999). Intercultural network theory: A cross-cultural paradigmatic approach to acculturation. International Journal of Intercultural Relations, 23, 629-658.

South Africa Info. (2010). SA aims for more graduates, artisans. [Online].Available from www.southafrica.info/about/education/skills-041110.htm\#ixzz1Zu565pnn

Spitzberg, B. H. (1997). A model of intercultural communication competence, in L.A. Samovar \& R.E. Porter (eds.), Intercultural communication: A reader, (379-391). Belmont, CA: Wadsworth.

Ting-Toomey, L. (1993). Communicative Resourcefulness. An Identity Negotiation Perspective', in R. L Wiseman \&J. Koester, (eds.), Intercultural Communication Competence, (72-111). Newbury Park, CA: Sage.

Wiseman, R. L. (2002). Intercultural Communication Competence, in W.B. Gudykunst \&B. Mody, (eds.), Handbook of International and Intercultural Communication, (207-224). Thousand Oaks: Sage. 